\title{
Management Information Systems, Conceptual Dimensions of Information Quality and Quality of Managerial Decisions: Modelling Artificial Neural Networks
}

\author{
Hossein Hakimpoor ${ }^{1, *}$, M. Khairabadi ${ }^{2}$ \\ ${ }^{1}$ Department of Management, Birjand Branch, Islamic Azad University, Birjand, Iran \\ ${ }^{2}$ Department of management, Payame Noor University, Tehran, Iran
}

Copyright $\mathrm{C} 2018$ by authors, all rights reserved. Authors agree that this article remains permanently open access under the terms of the Creative Commons Attribution License 4.0 International License

\begin{abstract}
The effect of information system on decision making is a central concern in the field of information system (IS). Information systems form the backbone of any business process integration and the main objective of information systems is helping decision makers by providing accurate and time based information helping them in making the right decisions in turbulent environment. The present study has been performed to examine the impact of using management information systems (MIS) and conceptual dimensions of information quality on the quality of managerial decisions in public organizations in Iran. Sample of the study was 250 of the managers from 17 public organizations that were chosen randomly and data was collected on 2015. Using artificial neural networks (ANN) analysis results show that MIS and conceptual dimensions of information quality have a positive effect on quality of managerial decisions and this effect is stronger when MIS and conceptual dimensions of information quality are merged.
\end{abstract}

Keywords Management Information Systems, Quality of Management Decisions, Artificial Neural Networks

\section{Introduction}

The role of Management Information Systems is described and analyzed in light of its capability for decision making and basically refers to a system that uses information in order to ensure apt management of businesses. Fundamentally, all the facets of MIS run concomitantly in order to ensure overall efficiency of the whole system. Management Information System (MIS) is basically concerned with the process of collecting, processing, storing and transmitting relevant information to support the management operations in any organizations. Thus, the success of decision-making, which is the heart of administrative process, is highly dependent partly on available information, and partly on the functions that are the components of the process. For example, if managerial objectives are absent or unclear, probably due to inadequate information, there is no basis for a search. Without information obtained through a search, there are no alternatives to compare, and without a comparison of alternatives the choice of a particular course of action is unlikely to yield the desired result. In other words effective decision making demands accurate, timely and relevant information [1].

Essentially, without the established systems of getting information in MIS, it would be extremely difficult for organizations to make their decisions. This is because they would be forced to making baseless information due to the lack of confirmed information. Moreover, MIS normally lays a firm foundation for the establishment of concrete decisions through its systematic tools, timely information and adequate managerial policies and regulations. Management Information Systems refers to a system that uses information in order to ensure apt management of businesses. Fundamentally, all the facets of MIS run concomitantly in order to ensure overall efficiency of the whole system [2].

\section{Literature Review}

The management information system collects the environmental data and records the organizational functions and exchanges and afterward fortress organizes and selects them and passes them over to the managers as 
they can produce their necessary information [3]. Therefor the management information system helps the organizations to collect, save revise the information. This act would be effective in cost reductions obtaining more data, more discipline through coordination of concepts of each subset as well as quick access of managers to their necessary information [4].The MIS and its organizational subsystems contribute to decision making process in many basic ways. Nowadays, some of the organizations use MIS to assistant managers for decision making. [5] has stated that making decisions is an important part of working in business environment. Companies develop a decision-making process based on individuals responsible for making decisions and the scope of the company's business operations. A useful tool for making business decisions is a management information system (MIS). In the other words: the MIS is an organization -wide effort to provide decision making process information. The system is a formal commitment by executive to make the computer available to all managers. The MIS sets the stage for accomplishments in the other area, which is DSS, the virtual office and knowledge based systems. The main idea behind the MIS is to keep a continuous supply of information flowing to the management. Afterward by data and information gathered from MIS system, make decisions [6].

Number of authors has discussed the role of information system in decision making. [1] investigated the use of management information system in decision-making on long-term planning, short-term planning and budgeting in the south-west Nigerian universities and conclude that there was a significant difference in the use of MIS for decision making on budgeting between federal and state universities in favor of the Federal universities. [6] has discussed two main information systems, namely, MIS and DSS, its characteristics, relation, and connections of each concept to decision-making process. [7] illustrated in his article the role of information systems in decision making. He stated that there is a significant relationship between information system and decision making. [8] Show the effect of using MIS on the quality of decision making by managers of Hamedan's tax administration and stated that MIS has significant effects on increasing the accuracy, speed and decreasing the time, complexity of decision making by managers. [2] has also stated the same statement about the relationship between MIS and decision making.

\section{The Methodology and Model}

A review of literature revealed that there is a need for research designed to advance our understanding of the effect of management information system on the quality of managerial decision which includes factors such as accuracy, speed, and easiness of making managerial decisions. From the other side the effect of MIS on the conceptual dimension of information quality (adopted from [7] ) has been analyzed which includes factors such as accuracy, relatedness and completeness of information. As it is illustrated in the research model (Figure 1) the effect of conceptual dimensions of information quality on the quality of managerial decisions is also analyzed.

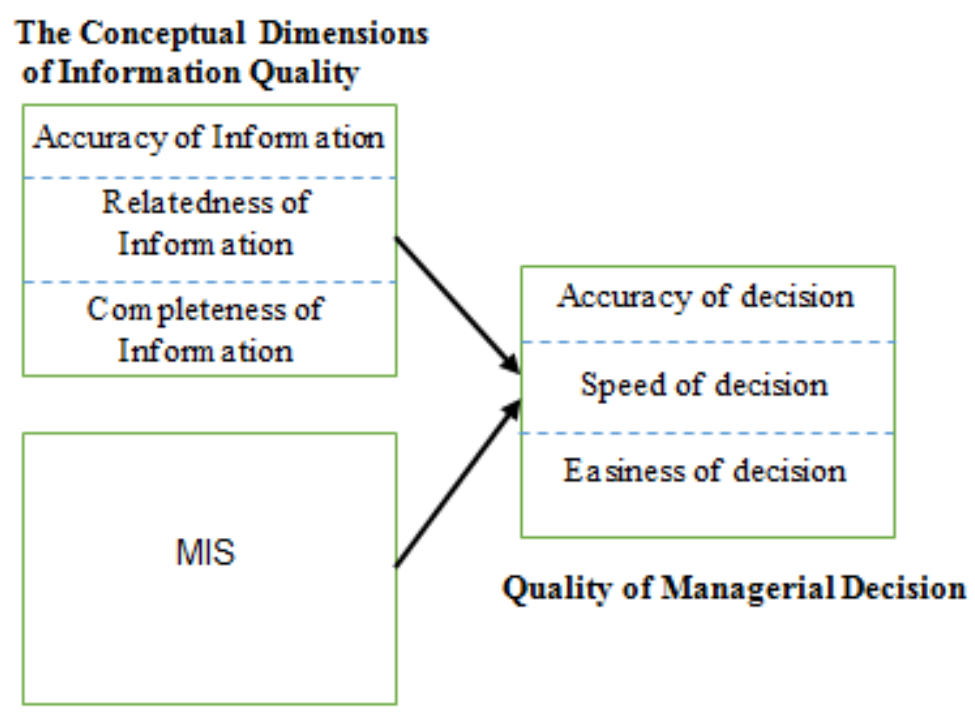

Figure 1. Research Model 
This study begins by sending an self-administrated questionnaire that mostly adopted from [7]. The managers are surveyed as respondents, because, they have a significant impact on managerial decisions specifically in public organizations. Considering the control variable, the stratified random sampling method was used for gathering quantitative data, because the stratifying criterion help researcher to be ensure that the resulting sample is distributed in the same way as the population [9]. The stratifying criterion was used in this study, namely the level of managers. The questionnaires were distributed between May to July 2015.17 public organizations have been randomly chosen out of 40 organizations in the list which has been provided by Southern Khorasan governor's office. The sample of the study was 250 of the managers (18 senior managers, 34 middle managers and 198 operational managers). A total number of 208 questionnaires have been completed and collected. Out of this amount 18 questionnaire belong to the senior managers, 41 questionnaires belong to the middle managers and 149 questioners belong to the operational managers. Item loadings, and average variance extracted values (AVE) are two methods to examine this validity. The AVE values of the variables, indicated in Table 1, are between 0.55 and 0.79 , providing more proof for convergent validity. As suggested by[10], all AVEs were above 0.5 indicating those constructs can explain high percentage of variance of the latent variable.

Table 1. AVE, CR, and Cronbach Alpha of the components

\begin{tabular}{|c|c|c|c|}
\hline components & $\begin{array}{c}\text { Cronbach } \\
\text { Alpha }\end{array}$ & $\begin{array}{c}\text { Composite } \\
\text { Reliability }\end{array}$ & AVE \\
\hline MIS & 0.830 & 0.910 & 0.55 \\
\hline $\begin{array}{c}\text { Accuracy of } \\
\text { Information }\end{array}$ & 0.858 & 0.923 & 0.60 \\
\hline $\begin{array}{c}\text { Relatedness of } \\
\text { Information }\end{array}$ & 0.700 & 0.886 & 0.63 \\
\hline $\begin{array}{c}\text { Completeness of } \\
\text { Information }\end{array}$ & 0.848 & 0.916 & 0.69 \\
\hline Accuracy of decision & 0.819 & 0.931 & 0.69 \\
\hline Speed of decision & 0.862 & 0.934 & 0.79 \\
\hline Easiness of decision & 0.704 & 0.887 & 0.60 \\
\hline
\end{tabular}




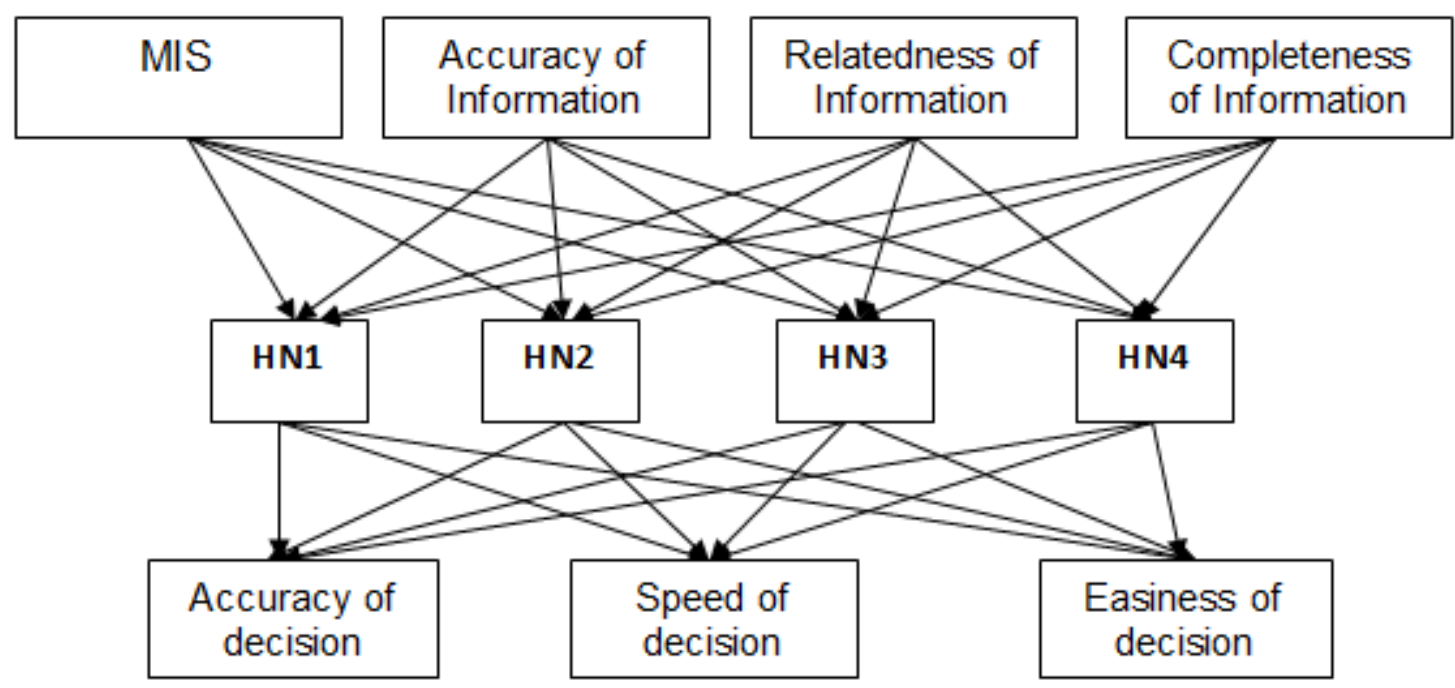

Figure 2. Architecture of research ANN model

\section{Data Analysis}

The first stage in data pre-processing and data screening was treating missing data and outliers. the researcher replaced missing values with the mean value of each variable as this is the most common method of missing data treatment among researchers [10]. The next stage in data screening process was detecting outliers. Outliers are cases that deviate so much from the other cases and lie outside of the general pattern of a distribution as to arouse suspicions that it was generated by a different mechanism [15]. Data outliers, when found, should be removed or replaced; all questionnaires were retained in this stage. The second stage in data pre-processing and data screening was testing data normality. Regarding in this study the mean squared error (MSE) function was used to optimize the connection weights in ANN models, the data need to be normally distributed in order to obtain optimal results[11].

There are several general data processing algorithms that removed the undesired variances and enhanced the information content on data. One technique is normalization which typically removes redundant information from a data set, compacting or making it invariant to one or more features. The principle of normalization is to reduce a vector (or data set) to a standard unit length, usually 1 . Furthermore it is necessary to re-scale all the inputs (normally between 0 and 1 or between -1 and 1). This is the required rescaling method for scale-dependent variables if the output layer uses the sigmoid activation function. In this research the sigmoid activation function was employed because compared with the other activation function (i.e. Hyperbolic tangent function) sigmoid activation function had less sum of squares error (SSE). According to [16] to scale the data for a particular input $\mathrm{X}$ :

\section{Scaled $X=(X-\min X) /(\max X-\min X)$.}

Data rescaling was done for all inputs in data set so that initially all the input variables had the same importance and during the learning phase the network deliberately altered the importance of variables, by changing the strengths of the connections between the input layer and the hidden layer. Finally the data set must be divided in two sets, a training set and a test set. In this research about $72 \%$ of data set (150) used for training the ANN and $28 \%$ of data set (58) used for testing and validation.

The next stage is the process of optimizing the connection weights that is known as 'training' or 'learning'. The process was conducted by changing the weights of each connection (iteratively and simultaneously) to minimize the error between desired output and actual output. In this research the training was done in batch mod. Batch mode updates the synaptic weights only after passing all training data records; that is, batch training uses information from all records in the training dataset. Batch training is often preferred because it forces the search to move in the direction of the true gradient at each weight update and it directly minimizes the total error and is most useful for "smaller" datasets [11].

The performance of the model has been judged based on prediction accuracy. As a measure of performance, the Sum-Squared-Error (SSE) and mean-squared-error (MSE) between the real amounts of performance parameters and the estimated amounts (ANN outputs) were compared. In this research the sigmoid activation function was employed in all layers because compared with the other activation function (Hyperbolic tangent and Linear function) and based on the Sum-Squared-Error (SSE) and mean-squared-error (MSE) as measure of performance, sigmoid activation function had less SSE and MSE (Table 2). 
Table 2. Network performance based on activation functions

\begin{tabular}{|c|c|c|c|}
\hline Transfer(activation) Function & Hyperbolic Tangent & Sigmoid \\
\hline Items & 0.753 & 0.681 & 0.760 \\
\hline Sum-squared-Error(SSE) & 58 & 58 & 58 \\
\hline Mean-squared-error(MSE) & 0.0132 & 0.0119 \\
\hline
\end{tabular}

Note: As previously discussed. In this research about $72 \%$ of data set (150) used for training the ANN and $28 \%$ of data set (58) used for testing and validation.

The $\mathrm{R}_{\mathrm{sq}}$ values also were calculated to evaluate the performance of the network model. $\mathrm{R}_{\mathrm{sq}}$ is the amount of variance of dependent variable(s) that is "accounted for" or "explained" by the independent variable(s). $R_{\mathrm{sq}}$ values of the endogenous variables are equal to the predictive power of the model. More precisely, $R_{s q}$ or $\left(R^{2}\right)$ is the squared product-moment correlation coefficient and varies between 0 and 1 and the closer this is to 1 the better the variation of the dependent variable is explained by the independent variable(s).For instance, if $\mathrm{R}_{\mathrm{sq}}$ is 1 then the independent variable is accounted for all the variation of the dependent variable. Thus, it can be concluded that the higher the $\mathrm{R}_{\mathrm{sq}}$ value, the greater the prediction ability of the model [10]. However, there is not any rule-of-thumb for making decision that what level or $\mathrm{R}_{\mathrm{sq}}$ is high enough, just its value can increase by adding more independent variables, even when the contribution of those variables is accidental or very small [17].

Table 3. Network performance based on $\mathrm{R}^{2}$ values

\begin{tabular}{|c|c|c|c|}
\hline Network performance & Accuracy of Decision & Speed of Decision & Easiness of Decision \\
\hline $\mathrm{R}^{2}$ & 0.519 & 0.549 & 0.602 \\
\hline MSE & 0.0011 & 0.0057 & 0.0060 \\
\hline RMSE & 0.0332 & 0.0755 & 0.0774 \\
\hline
\end{tabular}

The next stage was determination of the contribution of different factors to the networks. The contribution of different factors to the network was determined by the magnitude of their weighted connections (positive or negative) to the hidden nodes (Table 4).

Examination of the connections between hidden nodes and output nodes then showed the impacts which the hidden nodes (and thus their combinations of contributing factors) had on the performance output (Table 5). The connections that signed positively at either stage, had an enhancing effect upon the hidden or output nodes, while negatively signed connections had an inhibitory effect [18].

Table 4. Neural network topology on the linkage between main variables

\begin{tabular}{|c|c|c|c|c|c|c|}
\hline Predictor & \multicolumn{9}{|c|}{ To the hidden layer } \\
\hline \multirow{4}{*}{ From input layer } & & $\mathrm{H}(1: 1)$ & $\mathrm{H}(1: 2)$ & $\mathrm{H}(1: 3)$ & $\mathrm{H}(1: 4)$ & Total contribution \\
\cline { 2 - 7 } & (Bias) & .553 & .588 & 1.514 & .659 & 3.314 \\
\cline { 2 - 8 } & MIS & .405 & -1.023 & .821 & .378 & 2.627 \\
\cline { 2 - 8 } & Accuracy of information & .261 & .661 & .368 & -.076 & 1.366 \\
\cline { 2 - 8 } & Relatedness of information & .307 & .370 & .001 & .371 & 1.049 \\
\cline { 2 - 8 } & completeness of information & -.401 & -.408 & -.239 & .026 & 1.074 \\
\hline
\end{tabular}

Table 5. Impact of hidden nodes on output nodes

\begin{tabular}{|c|c|c|c|c|c|}
\hline \multicolumn{7}{|c|}{ From the hidden layer } \\
\hline To the output layer & (Bias) & HN1 & HN2 & HN3 & HN4 \\
\hline accuracy of Decision & -.028 & 0.116 & -1.341 & 0.797 & 0.614 \\
\hline Speed of Decision & -.578 & 0.347 & -0.999 & 1.049 & 0.959 \\
\hline Easiness of Decision & -0.870 & 1.016 & -0.619 & 1.137 & 0.750 \\
\hline Total contribution & 3.476 & 1.479 & 2.959 & 2.983 & 2.323 \\
\hline
\end{tabular}


Observing the finding of the network, the first factor of the input layer (MIS) has the highest total contribution (2.627) to the four hidden nodes comprising the hidden layer. The second highest total contribution comes from the Information accuracy factor (1.366), whereas the third node in input layer (relatedness of information) had the lowest level of the total impact of the hidden layer (1.049). According to the findings MIS and information accuracy factor have high contribution to the network $(2.627,1.366$ respectively) and relatedness of information have the lowest total contribution to the network (1.049).

As can be seen in Table 4, the strongest impact derived from the MIS input factor is directed to the hidden node 3 . Other input factors (accuracy of information and relatedness of Information) also have a contributory and positive weight on hidden node 3 On the other hand hidden node 3 had contributory weight impacting all output measures (see Table 5 for impact of hidden nodes on output nodes) revealed that combination of MIS factors and accuracy and relatedness of information have combination of contributing (positive) impact on the output $(1.137,1.049$ and 0.797 for easiness of decision, speed of decision and accuracy of decision respectively).

MIS, relatedness and completeness of information also have a contributory and positive weight on hidden node 4 and hidden node 4 had contributory weight impacting all output measures. MIS, accuracy and relatedness of information have a contributory and positive weight on hidden node 1 and hidden node 1 had contributory weight impacting all output measures. These findings can be interpreted as revealing the merged affects MIS and accuracy of information can have a positive impact on the output and this impact is stronger on easiness of decision and speed of decision rather than accuracy of decision.

The highest negative impacts (inhibitory weights) belong to MIS (-1.023) and completeness of information $(-0.408)$ and this hidden node (hidden node 2 ) showed a very high inhibitory (weight) effect on the output. These findings can be interpreted as that when the negative impact of MIS and conceptual dimension of information quality are merged together this will result to a very high negative impact on quality of managerial decision. It means that the companies who have higher level of MIS and at the same time have higher level of information quality will have higher level of quality of decision and vice versa.

With regard to contributory weights (positive impact) and inhibitory weights (negative impact) of every input factor to the hidden nodes and also the effect of hidden nodes on the output nodes it can be revealed that there is positive relationship between MIS and quality of managerial decision and this relationship is stronger with the conceptual dimension of information quality. To have clearer results about the influence of each input variable and its contribution to the output, independent variable analysis by connection weight method was done in the next section.

\subsection{Independent Variable Importance Analysis}

Importance analysis or input sensitivity analysis performs a sensitivity analysis, which computes the importance of each predictor in determining the neural network. The analysis is based on the combined training and testing samples. This method was used to determine the influence of each input variable and its contribution to the output. The larger the sum for a given input node, the more the importance of the corresponding input variable [19]. The relative importance of a given input variable can be defined as:

$$
R I=\sum_{H=1}^{h}\left(\mathrm{~W}_{\mathrm{I}-\mathrm{H}} \mathrm{W}_{\mathrm{H}-\mathrm{O}}\right)
$$

Where RI is the relative importance of the input variable $\mathrm{I}, \mathrm{h}$ is the total number of hidden nodes, $\mathrm{W}_{\mathrm{I}-\mathrm{H}}$ is the weight of the connection between input node I and hidden node $\mathrm{H}$, and $\mathrm{W}_{\mathrm{H}-\mathrm{O}}$ is the weight of the connection between hidden node $\mathrm{H}$ and output node. As can be seen in Table 6, MIS and accuracy of information have the highest importance to the network and consequently highest influence to the output factors.

Table 6. Input sensitivity analysis

\begin{tabular}{|c|c|c|}
\hline Factors & Importance & $\begin{array}{c}\text { Normalized } \\
\text { Importance }\end{array}$ \\
\hline MIS & 0.606 & $100 \%$ \\
\hline $\begin{array}{c}\text { accuracy of Information } \\
\text { Relatedness of } \\
\text { Information }\end{array}$ & 0.171 & $28.2 \%$ \\
\hline $\begin{array}{c}\text { Completeness of } \\
\text { Information }\end{array}$ & 0.134 & $14.8 \%$ \\
\hline
\end{tabular}

\section{Conclusions}

Result of analyses showed that MIS and conceptual dimension of information quality have a positive effect on quality of managerial decision and this effect is stronger when MIS and conceptual dimension of information quality are merged. In other words, companies who have higher information quality, the relationship between MIS and quality of managerial decision is stronger. Based on the neural network analysis, MIS is an important factor that had significant contributory effect on the decision making. Although, considering the other factors effect, the MIS contributory effect was higher on the decision making when the level of the conceptual dimension of information quality was higher and this impact is stronger on easiness of decision and speed of decision rather than accuracy of decision. Regarding to network performance and based on activation functions, In this research the sigmoid activation function was employed in all layers because compared with 
the other activation function (Hyperbolic tangent and Linear function) and based on the Sum-Squared-Error (SSE) and mean-squared-error (MSE) as measure of performance, sigmoid activation function had less (SSE) and (MSE) and it means there is a non-linear relationship between MIS and quality of managerial decisions. In other word having MIS can't necessarily guaranty quality of managerial decisions and having quality decisions needs accurate, related and complete information too.

\section{REFERENCES}

[1] I. A. AJAYI and F. F. OMIRIN, "The Use of Management Information Systems (MIS) In Decision Making In The South-West Nigerian Universities," Educational Research and Review, vol. 2, pp. 109-116, 2007.

[2] S. NOWDURI, "Management information systems and business decision making: review, analysis, and recommendations," Journal of Management and Marketing Research, vol. 7, 2011.

[3] R. G. MURDICK and J. C. MUNSON, MIS, concept and design. Prentice-Hall, Inc., 1986.

[4] D. C. Bose, Principles of Management and Administration. Delhi, 2012.

[5] D. J. POWER, Decision support systems: a historical overview, Handbook on Decision Support Systems. Berlin Heidelberg: Springers 2008.

[6] A. ASEMI and S. A., "The Role of Management Information System (MIS) and Decision Support System (DSS) for Manager's Decision Making Process," International Journal of Business and Management, vol. 6, 2011.

[7] M. ALKHAFFAF, "The Role of Information Systems in Decision Making: The case of Jordan Bank," Computer Engineering and Intelligent Systems, vol. 3, 2012.

[8] A. Ghadimie dehghanpour, R. Sohrabi, and H. Soleyman, "Evaluating the effectiveness of management information systems (MIS) on the ability of decision making of managers," presented at the 2nd National conference in Management science, Iran, 2014.
[9] A. BRYMAN, Social research methods. New York: Oxford, 2008.

[10] J. HAIR, R. ANDERSON, R. TATHAM, and C. WILLIAM, Multivariate data analysis. NJ: Prentice Hall, 1998.

[11] H. R. MAIER and G. C. DANDY, "neural network for prediction and forecasting of water resources variables: a review of modelling issues and applications," environmental modelling and software, vol. 15, pp. 101-124, 2000.

[12] M. Silva, L. MOUTINHO, A. COELHO, and A. MARQUES, "Market orientation and performance: modelling a neural network," European Journal of Marketing, vol. 43, pp. 421-437, 2007.

[13] P. A. PHILLIPS, F. M. DAVIS, and L. MOUNTINHO, "the interactive effects of strategic marketing planning and performance: a neural network analysis," Journal of Marketing management, vol. 17, pp. 159-182, 2001.

[14] O. SHARIATI, A. A. MOHD ZIN, A. KHAIRUDDIN, and M. R. AGHAMOHAMMADI, "Application of Neural Network Observer for On-line Estimation of Salient-Pole Synchronous Generators' Dynamic Parameters using the Operating Data," Electr Eng, Springer,, vol. 94, 2012.

[15] HANS-PETER KRIEGEL, P. KRöGER, and A. ZIMEK., "Outlier Detection Techniques," presented at the 16th ACM SIGKDD Conference on Knowledge Discovery and Data Mining, Munich, Germany., 2010.

[16] R.-S. GUH, "Effects of non-normality on artificial neural network based control chart pattern recognizer," Journal of the Chinese Institute of Industrial Engineers, vol. 19, 2002.

[17] M. SAFIEK, "The Influence of Religion on Retail Patronage Behavior in Malaysia," University of Stirling, UK, 2006.

[18] L. MOUTINHO and P. A. PHILLIPS, "the impact of strategic planning on the competitiveness, performance and effectiveness of bank branches: a neural network analysis " International Journal of Bank Marketing, vol. 20, pp. 102-110, 2002.

[19] M. PALIWAL and U. A. KUMAR, "Assessing the contribution of variables in feed forward neural network," Applied Soft Computing, vol. 11, pp. 3690-96, 2011. 